\title{
Determination of the Deuterium Abundances in Water from 156 to 10,000 ppm by SIFT-MS
}

\author{
Patrik Španěl, ${ }^{1,2}$ Violetta Shestivska, ${ }^{1}$ Thomas W.E. Chippendale, ${ }^{2}$ David Smith ${ }^{2}$ \\ ${ }^{1}$ J. Heyrovský Institute of Physical Chemistry, Academy of Sciences of the Czech Republic, Dolejškova 3, 182 23, Prague 8, \\ Czech Republic \\ ${ }^{2}$ Institute for Science and Technology in Medicine, School of Medicine, Keele University, Thornburrow Drive, Hartshill, \\ Stoke-on-Trent, ST4 7QB, UK
}

\begin{abstract}
In response to a need for the measurement of the deuterium (D) abundance in water and aqueous liquids exceeding those previously recommended when using flowing afterglow mass spectrometry (FA-MS) and selected ion flow tube mass spectrometry (SIFT-MS) (i.e. 1000 parts per million, ppm), we have developed the theory of equilibrium isotopic composition of the product ions on which these analytical methods are based to encompass much higher abundances of $D$ in water up to $10,000 \mathrm{ppm}$ (equivalent to $1 \%$ ). This has involved an understanding of the number density distributions of the $\mathrm{H}, \mathrm{D},{ }^{16} \mathrm{O},{ }^{17} \mathrm{O}$ and ${ }^{18} \mathrm{O}$ isotopes in the isotopologues of $\mathrm{H}_{3} \mathrm{O}^{+}\left(\mathrm{H}_{2} \mathrm{O}\right)_{3}$ hydrated ions (i.e. $\mathrm{H}_{9} \mathrm{O}_{4}{ }^{+}$cluster ions) at mass-to-charge ratios $(\mathrm{m} / \mathrm{z})$ of 73,74 and 75 , the relative ion number densities of which represent the basis of FA-MS and SIFT-MS analyses of D abundance. Specifically, an extended theory has been developed that accounts for the inclusion of $D$ atoms in the $m / z 75$ ions, which increasingly occurs as $D$ abundance in the water is increased, and which is used as a reference signal for the $m / z 74$ ions in the measurement of $D$ abundance. In order to investigate the efficacy of this theory, experimental measurements of deuterium abundance in standard mixtures were made by the SIFT-MS technique using two similar instruments and the results compared with the theory. It is demonstrated that the parameterization of experimental data can be used to formulate a simple calculation algorithm for real-time SIFT-MS measurements of $D$ abundance to an accuracy of $1 \%$ below $1000 \mathrm{ppm}$ and degrades to about $2 \%$ at $10,000 \mathrm{ppm}$.
\end{abstract}

Key words: Deuterium abundance, Total body water, Selected ion flow tube mass spectrometry, SIFT-MS, Stable isotopes

\section{Introduction}

Some 10 years ago we developed selected ion flow tube mass spectrometry (SIFT-MS) [1] and flowing afterglow mass spectrometry (FA-MS) [2], methods with the specific objective to determine in real time the abundance of deuterium (D) in water vapour containing $\mathrm{H}_{2} \mathrm{O}$, $\mathrm{HDO}$ and $\mathrm{D}_{2} \mathrm{O}$ molecules (i.e. the ratio of the number of $\mathrm{D}$ atoms to the total number of atoms of all hydrogen isotopes), from

Correspondence to: Patrik Španěl; e-mail: spanel@jh-inst.cas.cz which the $\mathrm{D}$ abundance in the associated liquid water phase can be derived [2-4]. Research has focused on the measurement of total body water (TBW) by analysing exhaled breath for HDO following the ingestion of an accurate amount of pure $\mathrm{D}_{2} \mathrm{O}$, exploiting the principle of isotope dilution $[4,5]$. Thus, the ingested $\mathrm{D}_{2} \mathrm{O}$ rapidly becomes $\mathrm{HDO}$ via fast isotopic exchange with the abundant body water molecules and after some time, typically $100 \mathrm{~min}$, the HDO is equilibrated throughout the body water, which is reflected in its level in the exhaled water vapour. Thus, in a series of longitudinal studies in close collaboration with our nephrology colleagues led by S.J. Davies, we have successfully exploited FA-MS to determine the TBW in significant 
cohorts of healthy volunteers and in patients suffering from renal disease who are being treated by haemodialysis and peritoneal dialysis $[6,7]$. This non-invasive, painless and rapid approach to the measurement of TBW is proving to be most valuable in nephrology.

The basic principle of FA-MS deuterium analysis is simple, but there are details that need to be understood to promote this method towards accurate analyses of $\mathrm{D}$ abundance and these important details are given in a later section. For the moment, the method is based on the creation of a swarm of water cluster ions, $\mathrm{H}_{3} \mathrm{O}^{+}\left(\mathrm{H}_{2} \mathrm{O}\right)_{3}$ (i.e. $\mathrm{H}_{9} \mathrm{O}_{4}{ }^{+}$), held in an inert support gas, usually helium, in the presence of water molecules at a constant, known temperature, for time periods sufficient to allow the $\mathrm{D},{ }^{17} \mathrm{O}$ and ${ }^{18} \mathrm{O}$ isotopologues of these cluster ions to reach their thermal equilibrium distribution. The abundance of $\mathrm{D}$ in the water vapour introduced into the support gas is then obtained by measuring the relative number densities of these isotopologues using quantitative mass spectrometry, as explained later. These isotopologue ions have mass-to-charge ratios $(\mathrm{m} / \mathrm{z})$ of $73\left(\mathrm{H}_{9}{ }^{16} \mathrm{O}_{4}{ }^{+}\right), 74\left(\mathrm{H}_{8} \mathrm{D}^{16} \mathrm{O}_{4}{ }^{+}\right.$and $\left.\mathrm{H}_{9}{ }^{16} \mathrm{O}_{3}{ }^{17} \mathrm{O}^{+}\right)$and $75\left(\mathrm{H}_{9}{ }^{16} \mathrm{O}_{3}{ }^{18} \mathrm{O}^{+}\right)$. More combinations are possible at $\mathrm{m} / \mathrm{z} 75$, including $\mathrm{H}_{8} \mathrm{D}^{16} \mathrm{O}_{3}{ }^{17} \mathrm{O}^{+}$and $\mathrm{H}_{7} \mathrm{D}_{2}{ }^{16} \mathrm{O}_{4}{ }^{+}$, but their expected contributions are negligible $(\ll 1 \%)$ at the natural abundances of the minor isotopes $\mathrm{D}$ and ${ }^{17} \mathrm{O}$ and for small $\mathrm{D}$ enrichments. However, contributions of the last two ions can become important if the number density of the HDO molecules in the analyte vapour is high enough; even isotopologue ions at $\mathrm{m} / \mathrm{z} 76$ can become significant at high HDO levels. These enrichment phenomena are the major focus of this paper in which we show how they can be accounted for and how SIFT-MS in addition to FA-MS can be used to accurately measure $\mathrm{D}$ abundances up to ten thousands of parts per million in water vapour and hence in liquid water using the appropriate vapour phase/liquid phase partition coefficients.

\section{SIFT-MS and FA-MS for Measurements of $D$ Abundance in Water Vapour}

These analytical methods evolved from the well-known selected ion flow tube and flowing afterglow, both fast flow tube/quantitative mass spectrometric techniques that have been used by us and others to study the kinetics of ion/ molecule reactions $[8,9]$ and recombination reactions [10]. Subsequently, these methods were adapted as the gas-phase analytical mass spectrometric techniques SIFT-MS and FAMS. SIFT-MS has been used to measure trace gas concentrations in air samples down to the parts per billion (ppb) level and below [11, 12] and is proving to be especially valuable for on-line, real-time analyses of exhaled breath. Our first exploratory studies on the measurement of the deuterium abundance in water vapour were carried out using an early SIFT-MS instrument of low sensitivity [1]. This involved the selective injection of $\mathrm{H}_{3} \mathrm{O}^{+}$ions (formed in an external microwave discharge) via an upstream quadrupole mass filter into helium carrier gas and the introduction into the carrier gas/ion swarm of water vapour (having an abundance of $\mathrm{D}$ atoms, later described by $R_{1}$ ) evolving from the liquid water for which the deuterium abundance was to be determined (later described as $R_{1 \text { liq }}$ ). Thus, the $\mathrm{H}_{3} \mathrm{O}^{+}$ions are converted to their hydrated isotopologues referred to above (i.e. water cluster ions at $\mathrm{m} / \mathrm{z}$ values 73,74 and 75 ). It is then a matter of measuring accurately the relative count rates of these ions and including them in the theoretical analysis described below, whence the abundance of $\mathrm{D}$ in the water vapour and then in the liquid water is determined. These initial SIFT-MS studies confirmed the soundness of this unique approach to $\mathrm{D}$ abundance measurements. Thus, by using standard $\mathrm{D}_{2} \mathrm{O} / \mathrm{H}_{2} \mathrm{O}$ mixtures the accuracy of measurement was confirmed [1], but the precision was found to be inadequate unless long integration times were used, because of the low ion count rates (counts per second) of the analytical $\mathrm{m} / \mathrm{z} 73,74$ and 75 ions (typically $2 \times 10^{4} \mathrm{c} / \mathrm{s}$ for $m / z 73$ ions and about 100 times lower for the $m / z 75$ ions) that could be created at the time of these initial studies in the old SIFT-MS instrument. It was then necessary to rethink the approach and this gave rise to our FA-MS method [2-4].

In FA-MS the upstream mass filter that is standard in SIFT-MS is absent and the precursor $\mathrm{H}_{3} \mathrm{O}^{+}$ions are formed by a weak microwave discharge through the helium carrier gas into which the water vapour to be analysed is introduced [13]. This results in much larger count rates of typically $2 \times$ $10^{6} \mathrm{c} / \mathrm{s}$ for $\mathrm{m} / \mathrm{z} 73$ ions and typically $10^{4} \mathrm{c} / \mathrm{s}$ for $\mathrm{m} / \mathrm{z} 74$ and 75 ions with a subsequent increase in the precision of the $\mathrm{D}$ abundance measurements reaching the desired $1 \%$ and better $[3,14]$. This allowed the TBW in human subjects to be determined to a comparable precision and accuracy (but see the important proviso and development described in the next paragraph). Much work in the measurement of TBW has been accomplished in collaboration with our clinical colleagues using FA-MS [5-7, 15-17]. However, this method does have a weakness in that by avoiding the upstream mass filter and directly discharging the helium carrier gas/water vapour mixture (which inevitably contains traces of air), ions like $\mathrm{NO}^{+}$and $\mathrm{O}_{2}^{+}$are formed in addition to $\mathrm{H}_{3} \mathrm{O}^{+}$and its hydrates. These $\mathrm{NO}^{+}$and $\mathrm{O}_{2}{ }^{+}$ions can undergo reactions with trace gases in the air/water vapour sample to be analysed, especially when the analyte is exhaled breath that contains carbon dioxide and many trace organic metabolite molecules, and these ill-defined ternary association reactions can produce "rogue ions" at the same $\mathrm{m} / \mathrm{z}$ value as the analytical $\mathrm{m} / \mathrm{z} 73,74$ and 75 ions that can diminish the accuracy of the determination of abundance of D. Whilst the influence of this interference can be minimized by software corrections, it is obviously undesirable. Fortunately, as we see below, the new generations of SIFT-MS instruments have much higher sensitivities implying that much greater count rates of injected $\mathrm{H}_{3} \mathrm{O}^{+}$ions can be produced and so it is now possible to revert back to SIFTMS and achieve the required precision and accuracy of 
measurements of D abundance, as is demonstrated by the results of the calibration experiments presented later.

Now an important technical aspect of SIFT-MS and FAMS measurements must be explained. The count rate of the ions at $\mathrm{m} / \mathrm{z} 73$ typically approaches $10^{6} \mathrm{c} / \mathrm{s}$, which is more than 100 times larger than those at $\mathrm{m} / \mathrm{z} 74$ and 75 . Clearly, for a measurement of the $\mathrm{D} / \mathrm{H}$ ratio to an accuracy of $1 \%$ or better, the ion detectors (usually electron multipliers with single or multiple channels or with discrete dynodes) should be capable of measuring - to a similar accuracy - ions count rates at $\mathrm{m} / \mathrm{z} 73$ of $10^{6} \mathrm{c} / \mathrm{s}$ and also those of the $\mathrm{m} / \mathrm{z} 74$ and 75 at count rates of typically $(4-10) \times 10^{3} \mathrm{c} / \mathrm{s}$. The statistical uncertainty in determining the lower count rates of the $\mathrm{m} / \mathrm{z}$ 74 and 75 ions can be decreased, and hence the precision of the measurements can be increased, by counting these ions for increasing time periods; single breath exhalations can be sustained for several seconds which is sufficient to realize good precision. However, the response of most detectors is not sufficiently fast that the high counts per second at $\mathrm{m} / \mathrm{z}$ 73 can be measured to the required accuracy. The solution to this problem is to avoid measurement of $\mathrm{m} / \mathrm{z} 73$ and to measure accurately the count rate of the isotopologue at $\mathrm{m} / \mathrm{z}$ 75 as a reference signal, assuming this to be independent of the deuterium abundance in the sample water vapour. Then the deuterium abundance can be obtained from simultaneous accurate measurements of the relative count rates of the $\mathrm{m} / \mathrm{z}$ 74 and 75 ions. Details of this approach are given in previous papers [2-4] and briefly summarized below.

The count rates at $m / z 74$ and 75 currently attainable by SIFT-MS are ideal for the available multipliers to handle and so measurement precision can be achieved. However, this approach does require that a correct value of the isotopic abundance of ${ }^{18} \mathrm{O}$ be adopted and it is also assumed that the $\mathrm{m} / \mathrm{z} 75$ ion consists only of $\mathrm{H}_{9}{ }^{16} \mathrm{O}_{3}{ }^{18} \mathrm{O}^{+}$ions (i.e. they contain just one ${ }^{18} \mathrm{O}$ atom and an insignificant fraction of $\mathrm{D}$ atoms). We have shown that these requirements are met when the deuterium abundance in the water vapour to be analysed is less than 1000 ppm and using FA-MS in this regime we have made many measurements on TBW in healthy controls and dialysis patients that demonstrate its validity [5-7]. But above about $1000 \mathrm{ppm}$ an increasing fraction of the $m / z 75$ ions become populated with a single $\mathrm{D}$ atom in combination with a single ${ }^{17} \mathrm{O}$ atom and/or two $\mathrm{D}$ atoms (see Figure 1 later), and this added complication must then be taken into account in order to obtain accurate deuterium abundances. In some applications of isotopic dilution, restricted volumes of water are involved and this results in a need for measurements of deuterium abundance in water at several thousand parts per million. Thus, it has become necessary to consider the extension of the theoretical analysis underlying the analytical methods. This has also demanded an experimental check on the efficacy of the extended theory using standard solutions of deuterated water. The comparison of this new theory and experiment is reported below and the approach to accurate measurements of deuterium abundance in water vapour at levels from $1000 \mathrm{ppm}$ up to $10,000 \mathrm{ppm}$ is indicated. So, in summary, the goal of this work is to find an empirical expression for the vapour phase $\mathrm{D}$ abundance $\left(R_{1}\right)$ in terms of the known oxygen isotopic abundances and the ratio of the measured $\mathrm{m} / \mathrm{z} 74$ and 75 peak heights in the mass spectrum.

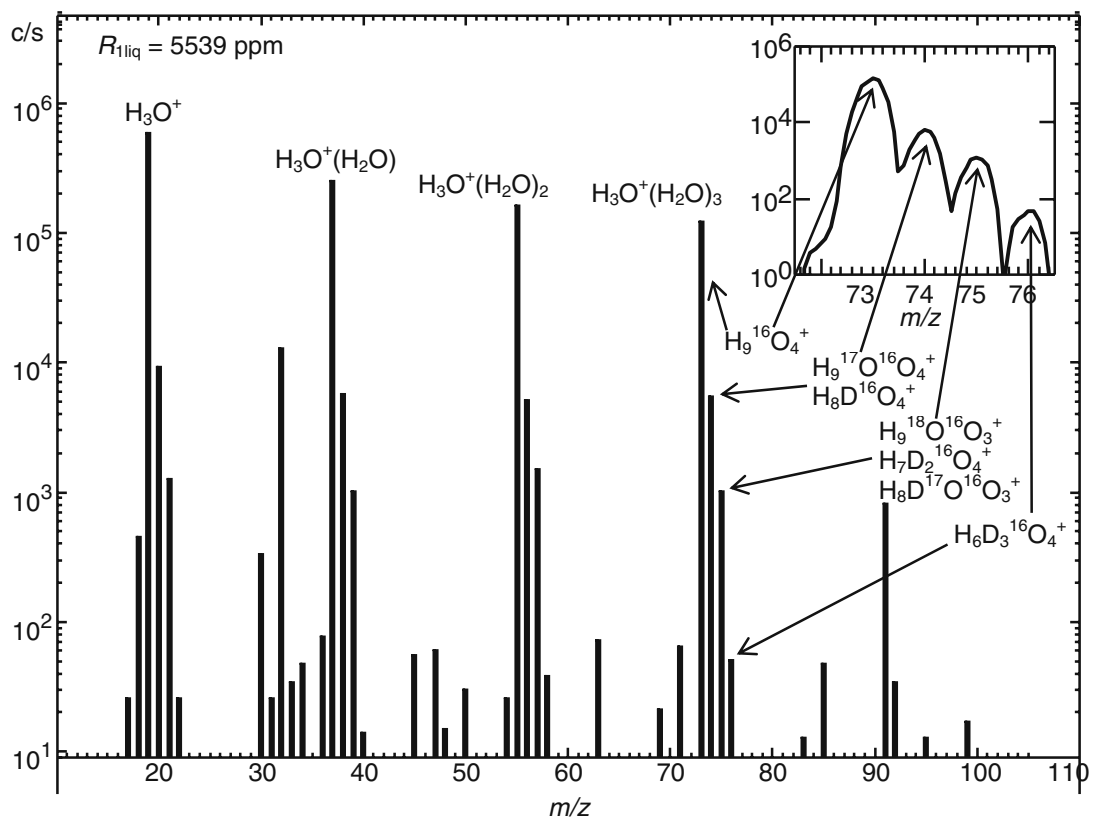

Figure 1. The SIFT-MS mass spectrum (counts per second, $\mathrm{c} / \mathrm{s}$ against ion mass-to-charge ratio, $\mathrm{m} / \mathrm{z}$ ) obtained for a standard mixture enriched to an $R_{1 \text { liq }}$ of $5539 \mathrm{ppm}$. The observed isotopologues of the trihydrate of $\mathrm{H}_{3} \mathrm{O}^{+}$are indicated in the inset 


\section{Theoretical Considerations}

The SIFT-MS and FA-MS methods for the determination of deuterium abundance in water vapour are based on the fact that deuterium/hydrogen isotope exchange is facile between the trihydrate hydronium ion $\mathrm{H}_{3} \mathrm{O}^{+}\left(\mathrm{H}_{2} \mathrm{O}\right)_{3}$ (i.e. $\mathrm{H}_{9} \mathrm{O}_{4}{ }^{+}$) and HDO in the gas phase, because there are no significant energy barriers and the enthalpy change is very small [18] in the isotope-exchange reactions:

$$
\mathrm{H}_{9} \mathrm{O}_{4}{ }^{+}(m / z 73)+\mathrm{HDO} \leftrightarrow \mathrm{H}_{8} \mathrm{DO}_{4}{ }^{+}(m / z 74)+\mathrm{H}_{2} \mathrm{O}
$$

As indicated, the reaction can proceed in both directions and dynamic equilibrium amongst the reacting ions is rapidly established at room temperature in the helium support gas of SIFT-MS. Then the distribution of the reacting ions is totally determined by the statistics of the isotope-exchange reactions and it is on this premise that the analysis below is based. Further details are given in previous papers [1,2]. A typical mass spectrum obtained by using SIFT-MS when the vapour above natural water enriched in $\mathrm{HDO}$ by the addition of $\mathrm{D}_{2} \mathrm{O}$ is introduced into an $\mathrm{H}_{3} \mathrm{O}^{+}$ion swarm is shown in Figure 1. Note the obvious presence of the isotopologues of the $\mathrm{H}_{3} \mathrm{O}^{+}\left(\mathrm{H}_{2} \mathrm{O}\right)_{0-3}$ cluster ions and the expansion of the spectrum around $\mathrm{m} / \mathrm{z} 73$ to 76 indicating the nature of these important isotopologue ions around which much of the discussion below revolves. Thus, the ions at $m / z 75$ are predominantly $\mathrm{H}_{9}{ }^{16} \mathrm{O}_{3}{ }^{18} \mathrm{O}^{+}$, but at high HDO concentrations $\mathrm{H}_{8} \mathrm{D}^{16} \mathrm{O}_{3}{ }^{17} \mathrm{O}^{+}$and $\mathrm{H}_{7} \mathrm{D}_{2}{ }^{16} \mathrm{O}_{4}{ }^{+}$ become significant contributors. Given the known abundances $[19,20]$ of the ${ }^{17} \mathrm{O}\left(R_{2}=0.00387\right)$ and ${ }^{18} \mathrm{O}\left(R_{3}=0.0198\right)$ in natural water, the contributions of these various isotopologues can be predicted statistically for varying abundance of $\mathrm{D}\left(=R_{1}\right)$ in the water vapour. Note that $R_{1}$ is proportional to the $\mathrm{D}$ abundance in the liquid water from which the vapour is derived and they are related by the known, temperature-dependent, partition coefficient of HDO between the liquid and vapour phases [21].

The equilibrium fractions $(I)$ of each isotopologue ion at $m / z 75\left(\mathrm{H}_{9}{ }^{16} \mathrm{O}_{3}{ }^{18} \mathrm{O}^{+}, \mathrm{H}_{8} \mathrm{D}^{16} \mathrm{O}_{3}{ }^{17} \mathrm{O}^{+}\right.$and $\left.\mathrm{H}_{7} \mathrm{D}_{2}{ }^{16} \mathrm{O}_{4}{ }^{+}\right)$within the total of all possible $\mathrm{H}_{9} \mathrm{O}_{4}{ }^{+}$isotopologues can be expressed as:

$$
\begin{gathered}
I\left[\mathrm{H}_{9}^{16} \mathrm{O}_{3}^{18} \mathrm{O}^{+}\right]=4\left(1-R_{1}\right)^{9}\left(1-R_{2}-R_{3}\right)^{3} R_{3} \\
I\left[\mathrm{H}_{8} \mathrm{D}^{16} \mathrm{O}_{3}^{17} \mathrm{O}^{+}\right]=36\left(1-R_{1}\right)^{8} R_{1}\left(1-R_{2}-R_{3}\right)^{3} R_{2} \\
I\left[\mathrm{H}_{7} \mathrm{D}_{2}^{16} \mathrm{O}_{4}^{+}\right]=36\left(1-R_{1}\right)^{7} R_{1}^{2}\left(1-R_{2}-R_{3}\right)^{4}
\end{gathered}
$$

Here, the $\left(1-R_{1}\right)$ factors correspond to the abundance of the major ${ }^{1} \mathrm{H}$ isotopes amongst all hydrogen atoms and the $\left(1-R_{2}-R_{3}\right)$ factors correspond to the abundance of ${ }^{16} \mathrm{O}$ amongst all $\mathrm{O}$ atoms. Four and 36 are the numbers of different combinations of atomic positions contributing to the specific isotopologues. The exponents directly correspond to the number of atoms of the given isotope in the molecular ion. To repeat, these equations are derived by assuming there are insignificant enthalpy changes in all these isotope-exchange reactions and that the equations only describe truly statistical mixing of isotopes in the ions. A graphical representation of the equilibrium fractions calculated from Equations (2) to (4) are shown in Figure 2a.

The insets in this figure indicate the variations in the equilibrium fractions of the $\mathrm{H}_{9}{ }^{16} \mathrm{O}_{3}{ }^{18} \mathrm{O}^{+}$and $\mathrm{H}_{7} \mathrm{D}_{2}{ }^{16} \mathrm{O}_{4}{ }^{+}$ isotopologues at deuterium abundances below $1000 \mathrm{ppm}$ for which previous work has shown that $m / z 75$ is a reliable reference level for measurements of $\mathrm{D}$ abundance [3]. Whilst there clearly is a diminution of the $\mathrm{H}_{9}{ }^{16} \mathrm{O}_{3}{ }^{18} \mathrm{O}$ ${ }^{+}$fraction with increasing $R_{1}$, it is less than $0.5 \%$ of the initial (zero $\mathrm{D} / \mathrm{H})$ fraction, as indicated previously. Similarly, the increase in the fraction of the doubly deuterated ion $\mathrm{H}_{7} \mathrm{D}_{2}{ }^{16} \mathrm{O}_{4}{ }^{+}$is commensurately small and so the total signal of $\mathrm{m} / \mathrm{z} 75$ can be considered to be devoid of the $\mathrm{H}_{7} \mathrm{D}_{2}{ }^{16} \mathrm{O}_{4}{ }^{+}$ions at these low $R_{1}$ values. However, major changes of the nature of the $\mathrm{m} / \mathrm{z} 75$ isotopologues occur with increasing $R_{1}$, the $\mathrm{H}_{7} \mathrm{D}_{2}{ }^{16} \mathrm{O}_{4}{ }^{+}$becoming an increasing fraction and the $\mathrm{H}_{9}{ }^{16} \mathrm{O}_{3}{ }^{18} \mathrm{O}^{+}$becoming a decreasing fraction, and the total ion signal at $\mathrm{m} / \mathrm{z} 75$ (also indicated in Figure 1a) significantly increases. Obviously, this needs to be accounted for if $m / z 75$ is to be used as a reference for measurements of $R_{1}$ in the range from 1000 to $11,000 \mathrm{ppm}$, as described below.

A similar analysis, again taken relative to the total ion signal intensity of all $\mathrm{H}_{9} \mathrm{O}_{4}{ }^{+}$ions, can be made for the two isotopologues contributing to $\mathrm{m} / \mathrm{z} 74$ (see Figure 1) as:

$$
\begin{gathered}
I\left[\mathrm{H}_{9}^{16} \mathrm{O}_{3}^{17} \mathrm{O}^{+}\right]=4\left(1-R_{1}\right)^{9}\left(1-R_{2}-R_{3}\right)^{3} R_{2} \\
I\left[\mathrm{H}_{8} \mathrm{D}^{16} \mathrm{O}_{4}^{+}\right]=9\left(1-R_{1}\right)^{8} R_{1}\left(1-R_{2}-R_{3}\right)^{4}
\end{gathered}
$$

The results of this analysis are graphically represented in Figure 2b. The inset shows the variation of the $\mathrm{H}_{9}{ }^{16} \mathrm{O}_{3}{ }^{17} \mathrm{O}^{+}$fraction as calculated from Equation (5), which is about $0.15 \%$ and decreases only slightly even at much higher $R_{1}$. Obviously, the fraction of $\mathrm{H}_{8} \mathrm{D}^{16} \mathrm{O}_{4}{ }^{+}$ will proportionately increase with increasing $R_{1}$ (this is the principle on which the measurement of $R_{1}$ depends!) reaching close to $10 \%$ at the highest $R_{1}$ considered, as calculated from Equation (6) and shown in Figure 2b. The total ion counts at $m / z 74$ are also shown, as obtained by simply summing the contributions of the two isotopologues, indicating the diminishing but still significant contribution of $\mathrm{H}_{9}{ }^{16} \mathrm{O}_{3}{ }^{17} \mathrm{O}^{+}$at high $R_{1}$. 

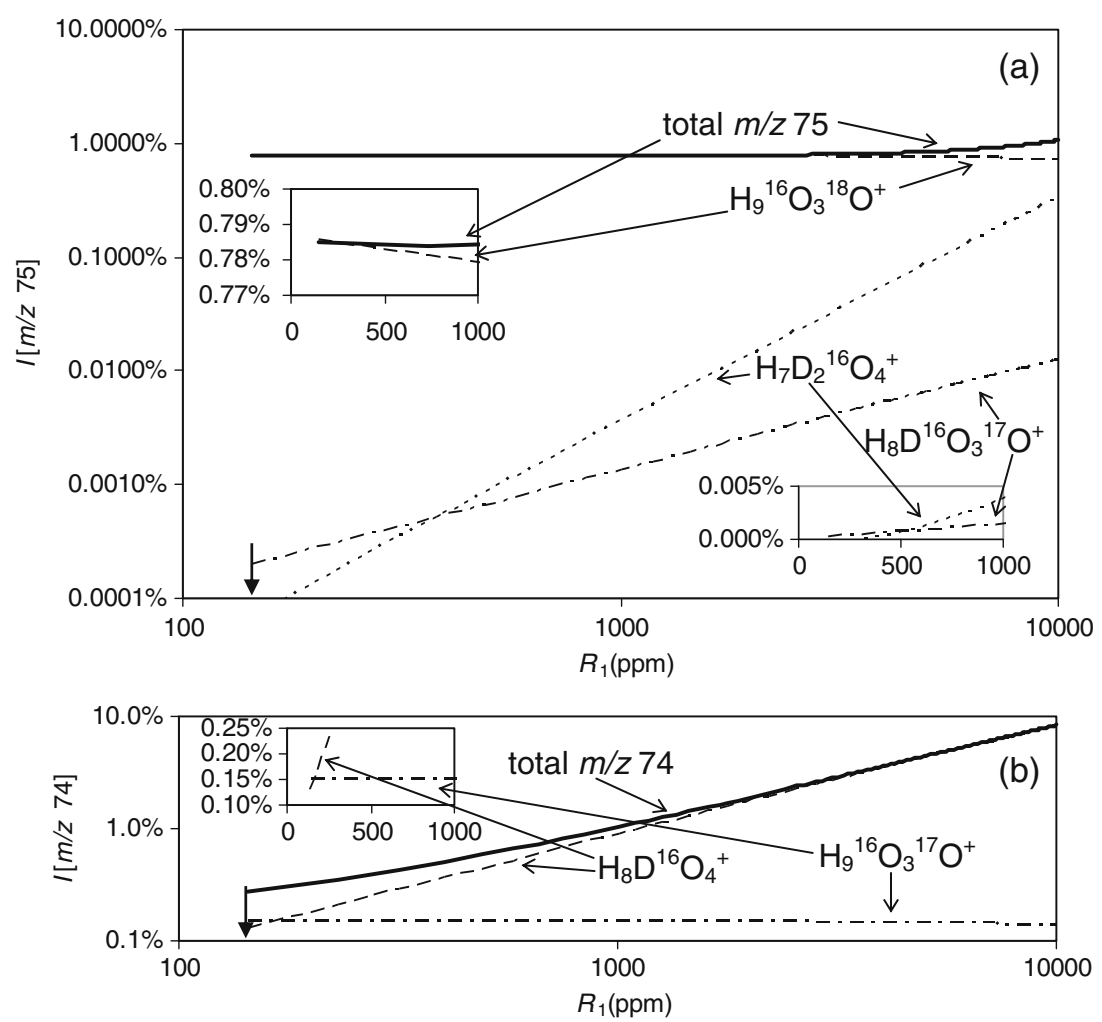

Figure 2. The percentages $(I)$ of the minor isotopologues of $\mathrm{H}_{9} \mathrm{O}_{4}{ }^{+}$ions from the total concentration of all possible isotopologues calculated as a function of $R_{1}$, the equilibrium abundance of $D$ in the water vapour in the helium carrier gas, as calculated by using Eqs. (2) to (6). (a) Contributions to the total count rate at $\mathrm{m} / \mathrm{z} 75$. The contributions of the $\mathrm{D}_{2}$ and $\mathrm{D}^{17} \mathrm{O}$ isotopologues increase with $R_{1}$ increases but both are insignificant below $1000 \mathrm{ppm}$. (b) Contributions to the total count rate at $\mathrm{m} / \mathrm{z}$ 74. The ${ }^{17} \mathrm{O}$ isotopologue is important below $R_{1}$ of $1000 \mathrm{ppm}$ but decreases at higher abundances of D. Vertical arrows indicate the value $R_{1}=144 \mathrm{ppm}$ corresponding to natural abundance of $\mathrm{D}$ in water $R_{1 \text { liq }}=156 \mathrm{ppm}$

Now it is possible to write a rigorous equation relating the observed ratio of equilibrium ion densities at $\mathrm{m} / \mathrm{z} 74$ to $\mathrm{m} / \mathrm{z}$ 75 , which we designate $Q=[74] /[75]$ (see $[2,3]$ ) as:

$Q=\frac{9 R_{1}\left(1-R_{1}\right)\left(1-R_{2}-R_{3}\right)+4\left(1-R_{1}\right)^{2} R_{2}}{4\left(1-R_{1}\right)^{2} R_{3}+36 R_{1}\left(1-R_{1}\right) R_{2}+36 R_{1}^{2}\left(1-R_{2}-R_{3}\right)}$

This rigorous equation can be compared with the approximate equation used previously in routine FA-MS analyses $[2,3]$ :

$$
Q=\left(9 R_{1}+4 \mathrm{R}_{2}\right) / 4 R_{3}
$$

In the range of $R_{1}$ up to 0.001 (i.e. D abundance of $1000 \mathrm{ppm}$ ) the difference in $Q$ derived from Equations (7) and (8) is less than $0.5 \%$, but for higher $R_{1}$ the discrepancy becomes very significant. Note that the linear relation between $Q$ and $R_{1}$ given by Equation (8) can easily be implemented for the analysis of $R_{1}$, and it is this that has been adopted for all our previous on-line, real-time measurements of $R_{1}$ in the water vapour above aqueous liquids and in exhaled breath $[2,3,13]$. However, the use of the exact Equation (7) involves the solution of a complex quadratic equation, which is feasible analytically, but more complicated to implement. Thus, it is desirable to formulate and parameterize a practical expression or algorithm for deriving $R_{1}$ from the measured $Q$ obtained for $R_{1}$ values above $1000 \mathrm{ppm}$ where Equation (8) would lead to significant errors. Such an expression will be presented later (as Equation 9) after discussing the experimental results.

So Equation 7, together with experimental measurement of $Q$, can be used to determine $R_{1}$ above $1000 \mathrm{ppm}$. But clearly it is essential to check experimentally the efficacy of this theoretical analysis by using prepared standard mixtures of deuterated water with known $R_{1}$. The results obtained from such experiments are reported in the next section.

\section{Experimental Work and Comparison with Theory}

\section{Materials and Methods}

These experiments were conducted by using two SIFT-MS instruments of the latest generation in Prague (Profile 3 manufactured by Instrument Science Limited, Crewe, UK) 
and at Keele (SIFT-MS instrument manufactured by Trans Spectra Limited, Newcastle-under-Lyme, UK) that realize close to $10^{6} \mathrm{c} / \mathrm{s}$ of the $m / z 73 \mathrm{H}_{9} \mathrm{O}_{4}^{+}$ions $[12,22,23]$. The flow rate of sampled air was configured such that the flow tube pressure in the absence of He carrier gas was about 0.15 Torr and then the experiments were carried out with total flow tube pressure of sample and carrier gas of about 1 Torr. Two separate approaches were carried out to experimentally determine the dependence of $Q$ on the deuterium enrichment of tap water. In one approach (Prague) a number of standard mixtures were prepared volumetrically, either by adding constant amounts of $\mathrm{D}_{2} \mathrm{O}(99.9 \%$ purity, Isotech Inc., USA) to a known volume of tap water or by sequential factoring of two dilutions of a known "mother solution" (10,000 ppm). The equilibration time for each sample was at least $60 \mathrm{~min}$ at room temperature $\left(22{ }^{\circ} \mathrm{C}\right)$ to allow for the $\mathrm{D}_{2} \mathrm{O} / \mathrm{H}_{2} \mathrm{O}$ isotope-exchange reaction (equilibration) times [24]. Our preliminary experiments have shown that an approach to equilibrium mixing can be observed during the first 10 min following the addition of pure $\mathrm{D}_{2} \mathrm{O}$ to tap water. In a second approach (Keele) the gravimetric method was used in which accurately weighed amounts of $\mathrm{D}_{2} \mathrm{O}$ were added to accurately weighed amounts of tap water.

The prepared samples were placed in bottles sealed by septa and the liquid water/water vapour headspace (in atmospheric air) was allowed to equilibrate at a constant temperature of $20^{\circ} \mathrm{C}$ for a few minutes. The septa were then pierced by a needle connected to the sample inlet line of the SIFT-MS instrument when the headspace air/water vapour mixture flowed into the helium carrier gas into which $\mathrm{H}_{3} \mathrm{O}^{+}$ ions had been selectively injected. Thus, hydration of the $\mathrm{H}_{3} \mathrm{O}^{+}$rapidly occurred and the isotope-exchange reactions indicated in Equation (1) proceeded to equilibrium. Hence, the count rates of the $\mathrm{m} / \mathrm{z} 74$ and 75 ions were accurately measured (each at four different positions on the peak produced by quadrupole mass spectrometer, see [2]), whence the $Q$ values were calculated as the count rate ratio [74]/[75]. At the onset it is essential to understand that it is tacitly assumed that ion number densities of the various ions in the helium carrier gas of the SIFT-MS (to which the analytical equations above relate) are directly related to their count rates as detected by the analytical mass spectrometer. This is only true if there is no discrimination in the mass spectrometer sampling/detection system between the analytical ions at $\mathrm{m} / \mathrm{z} 74$ and 75 . We consider this to be a valid assumption and this is discussed further in [23].

\section{Results}

The results are shown in Figure $3 \mathrm{a}$ as the dependence of the experimentally determined $Q$ on the known $R_{1 \text { liq }}$ in the standard samples. The data points from the two independent experiments in Prague and Keele are shown and the continuous solid line is a result of theory using Equation (7) after converting $R_{1 \text { liq }}$ to $R_{1}$ using the known partition coefficient $K_{1}=0.92$ between liquid and vapour concentrations of $\mathrm{HDO}$ at $20^{\circ} \mathrm{C}$ [21], while the dashed line represents the previously used linear relation (Equation 8). The inset is the plot of the experimental points obtained below $R_{1 \text { liq }}=$ $1400 \mathrm{ppm}$, which is closely linear and shows agreement between experiment and the theory to within $1 \%$, as we have previously shown for both FA-MS data [3] and the very early SIFT-MS data [1]. However, the departure from linearity at the highest $R_{1 \text { liq }}$ values is stark, the difference between the experimental values of $Q$ and those predicted by the simple theory reaching $2 \%$ at $2000 \mathrm{ppm}, 10 \%$ at $5000 \mathrm{ppm}$ and $30 \%$ at $10,000 \mathrm{ppm}$. But the theoretical curve for $Q$ against $R_{1 \text { liq }}$ derived by using the precise Equation (7) closely matches the experimental results in both form and magnitude. So the theory properly accounts for the changing composition of the $\mathrm{m} / \mathrm{z} 74$ and especially of the major changes that occur in the composition of $m / z 75$ with increasing $R_{1}$. At the largest $\mathrm{D}$ abundances investigated (about 10,000 ppm) there is about 3\% difference between the experimental and theoretical values of the ratio $Q$, and both differ from the result of the simple Equation (8) by about $30 \%$.

On the basis of these experimental results it is now possible to parameterize a correction that must be applied to the results calculated by using Equation (8) in order to obtain accurate values of $R_{1}$ from experimentally measured $Q$ values, as

$$
R_{1}=\frac{4\left(R_{3} \mathrm{Q}-\mathrm{R}_{2}\right) / 9}{1-0.0061(Q-0.19)^{2}}
$$

The numerator in Equation (9) represents the solution to Equation (8) with respect to $R_{1}$ and the denominator is a parameterized correction factor obtained by a least-squares fit through the experimental data points. It is important to note here that the unknown $R_{1}$ value itself cannot be used as a variable in the parameterization if a straightforward (not iterative) calculation algorithm is to be proposed.

Figure $3 \mathrm{~b}$ shows a plot of the expected values of $R_{1 \text { liq }}$ (standard mixtures) and those derived by using Equation (9) together with the known partition coefficient $K_{1}=0.92$ [21]. Note that using this simple correction in Equation (9), one achieves excellent linearity and near perfect agreement between the measured and expected $R_{1 \text { liq }}$ and also that the correction does not greatly influence the values within the low D abundance range up to $1300 \mathrm{ppm}$ (actually the correction at $1000 \mathrm{ppm}$ amounts to only $0.7 \%$ ). Because Equation (9) is based on the fit through the experimental data and not the theoretical predictions, it negates the 3\% difference between theory and experiment mentioned above. Note also that for increasing $R_{1 \text { liq }}$ the measurements become less precise, because a given error in the experimental $Q$ is projected as an increasingly larger error in the derived $R_{1 \text { liq. }}$. An error analysis of Equation (9) shows that a $1 \%$ error in the measured $Q$ corresponds at $1000 \mathrm{ppm}$ to a $1.1 \%$ error in $R_{1 \text { liq }}$, but at $10,000 \mathrm{ppm}$ this error is $2 \%$. At even higher 

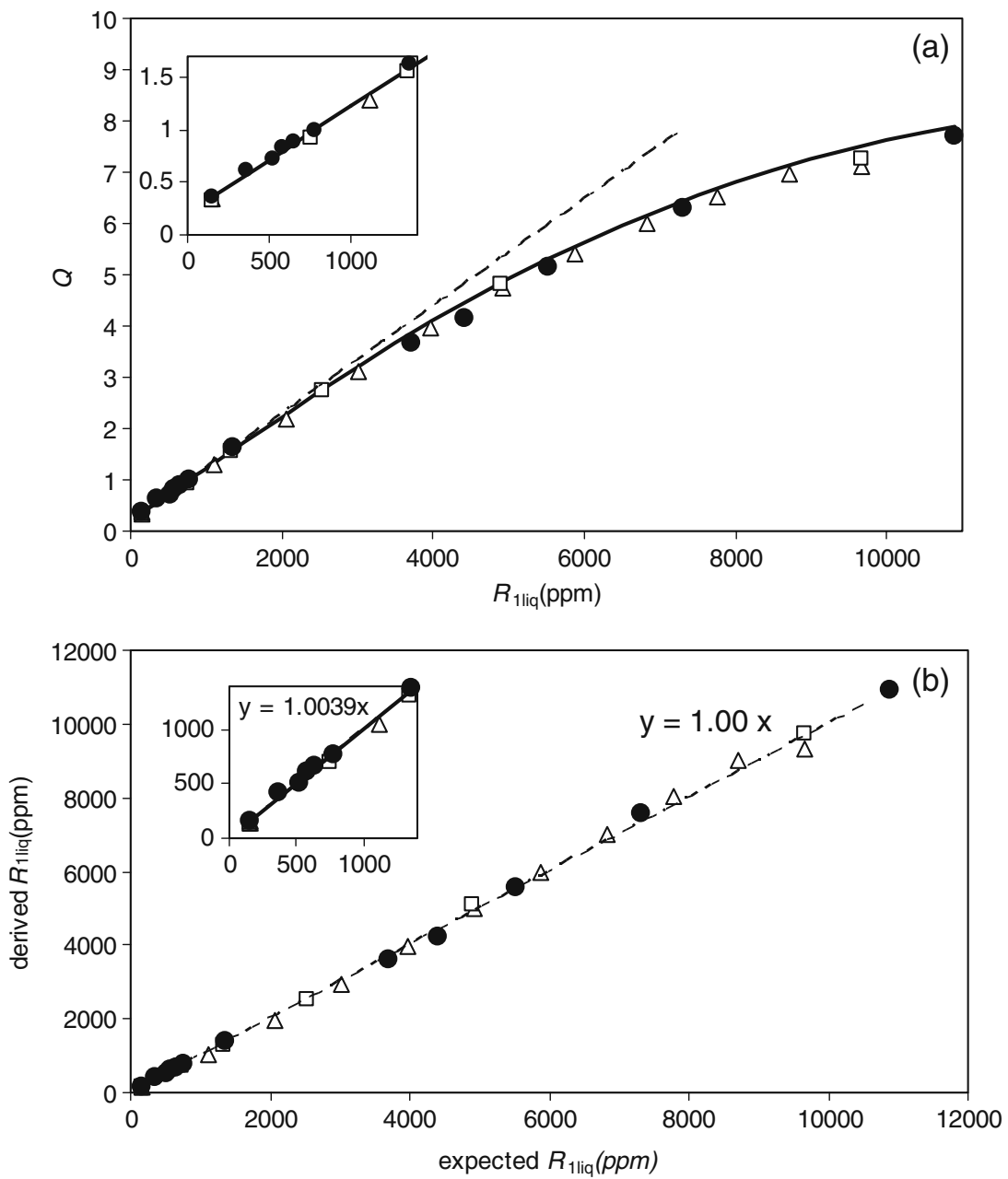

Figure 3. (a) Experimentally determined $Q=[74] /[75]$ as a function of the known $R_{1 \text { liq }}$ in standard mixtures. The solid circles are the results of measurements of gravimetrically prepared mixtures (Keele instrument), the open triangles are results from volumetrically prepared mixtures obtained by using incremental additions and the open squares are results from volumetric mixtures obtained by sequential dilutions (Prague instrument). The solid line is the value of $Q$ predicted by the theoretical Eq. (7) and the dashed line corresponds to the previously used approximate Eq. (8). (b) $R_{1 \text { liq }}$ values derived from measured $Q$ values using the new empirical Eq. (9) with a correction factor $1 /\left[1-0.0061(Q-0.19)^{2}\right]$ obtained by fitting the data from (a), which shows the good agreement with the expected standard mixture values

deuterium concentrations the variation of $Q$ with $R_{1 \text { liq }}$ is more gradual and so the present method of measurement of $R_{1}$ cannot be used reliably, because information on $\mathrm{m} / \mathrm{z} 76$ ions (see Figure 1) or even higher $\mathrm{m} / \mathrm{z}$ ions would have to be included, which would seriously complicate the analysis with the consequent reduction in precision and accuracy.

\section{Discussion and Concluding Remarks}

The critical message to be taken from these results is that the experiments show that the theory described by Equations (2) through (7) closely models the statistics of the isotope-exchange reactions and so within the stated uncertainty it can be used in association with experimental $Q$ measurements obtained by SIFT-MS to accurately determine deuterium abundances up to levels up to $10,000 \mathrm{ppm}$, as was intended in this work. This is remarkable in view of the complexity of the ion chemistry and the many isotope-exchange reactions involved. In fact, the situation in detail is even more complex than we have described. Inspection of the SIFT-MS spectrum shown in Figure 1 obtained for water vapour enriched to $\mathrm{D}$ abundance of about $5000 \mathrm{ppm}$ reveals the presence of ions at $\mathrm{m} / \mathrm{z} 76$, which we have not included in our analysis because it would add another degree of complexity. At this point, we conclude that the theory has been taken as far as is sensible and if it is to be used in association with $Q$ measurements to determine $\mathrm{D} / \mathrm{H}$ values around $10,000 \mathrm{ppm}$ then an uncertainty of about $3 \%$ would have to be accepted. The small discrepancy between the statistical theory and the experimental results may be related to small enthalpy changes in reaction (1) or in its analogue involving incorporation of a second D atom into the product ions. However, a bona fide approach, which bypasses the need for even more complex theory, is to curve fit (parameterize) the experimental data obtained by using standard mixtures, as is shown in Figure $3 \mathrm{~b}$. 
The statistical theory serves as a solid foundation and qualitatively explains the sources of non-linearity; the experimental calibration is used to enhance the accuracy of measurement beyond the limits imposed by the necessary and inherent assumptions. This approach allows $R_{1}$ values above $1000 \mathrm{ppm}$ and up to $10,000 \mathrm{ppm}$ to be determined to better than $2 \%$ by using SIFT-MS.

\section{References}

1. Španěl, P., Smith, D.: Selected ion flow tube mass spectrometry analyses of stable isotopes in water: Isotopic composition of $\mathrm{H}_{3} \mathrm{O}^{+}$and $\mathrm{H}_{3} \mathrm{O}^{+}\left(\mathrm{H}_{2} \mathrm{O}\right)_{3}$ ions in exchange reactions with water vapor. J. Am. Soc. Mass Spectrom.11, 866-875 (2000)

2. Smith, D., Španěl, P.: On-line determination of the deuterium abundance in breath water vapour by flowing afterglow mass spectrometry with applications to measurements of total body water. Rapid Commun. Mass Spectrom.15, 25-32 (2001)

3. Španěl, P., Smith, D.: Accuracy and precision of flowing afterglow mass spectrometry for the determination of the deuterium abundance in the headspace of aqueous liquids and exhaled breath water. Rapid Commun. Mass Spectrom.15, 867-872 (2001)

4. Davies, S., Španěl, P., Smith, D.: Rapid measurement of deuterium content of breath following oral ingestion to determine body water. Physiol. Meas.22, 651-659 (2001)

5. Smith, D., Engel, B., Diskin, A.M., Španěl, P., Davies, S.J.: Comparative measurements of total body water in healthy volunteers by online breath deuterium measurement and other near-subject methods. Am. J. Clin. Nutr.76, 1295-1301 (2002)

6. Chan, C., McIntyre, C., Smith, D., Španěl, P., Davies, S.J.: Combining near-subject absolute and relative measures of longitudinal hydration in hemodialysis. Clin. J. Am. Soc. Nephrol.4, 1791-1798 (2009)

7. Chan, C., Smith, D., Španěl, P., McIntyre, C.W., Davies, S.J.: A noninvasive, on-line deuterium dilution technique for the measurement of total body water in haemodialysis patients. Nephrol. Dial. Transplant.23, 2064-2070 (2008)

8. Ferguson, E., Fehsenfeld, F., Schmeltekopf, A.: Flowing afterglow measurements of ion-neutral reactions. Adv. At. Mol. Phys.5, 1-56 (1969)

9. Adams, N.G., Smith, D.: Selected ion flow tube (SIFT) - technique for studying ion-neutral reactions. Int. J. Mass Spectrom. Ion Process.21, 349-359 (1976)

10. Španěl, P., Dittrichova, L., Smith, D.: FALP studies of the dissociative recombination coefficients for $\mathrm{O}_{2}^{+}$and $\mathrm{NO}^{+}$within the electron temperature range $300 \mathrm{~K}$ to $2000 \mathrm{~K}$. Int. J. Mass Spectrom. Ion Proc.12, 183-191 (1993)
11. Smith, D., Španěl, P.: Selected ion flow tube mass spectrometry (SIFTMS) for on-line trace gas analysis. Mass Spectrom. Rev.24, 661-700 (2005)

12. Španěl, P.; Smith, D.: Progress in SIFT-MS; breath analysis and other applications. Mass Spectrom. Rev. (2010), doi:10.1002/mas.20303.

13. Spaněl, P., Smith, D.: Selected ion flow tube mass spectrometry (SIFTMS) and flowing afterglow mass spectrometry (FA-MS) for the determination of the deuterium abundance in water vapour. In: de Groot, P.A. (ed.) Handbook of Stable Isotope Analytical Techniques, pp. 88-102. Elsevier, Amsterdam (2004)

14. Spanêl, P.: Flowing afterglow mass spectrometry (FA-MS) for the determination of the deuterium abundance in breath water vapour and aqueous liquid headspace. In: Smith, D., Amann, A. (eds.) Breath Analysis for Clinical Diagnosis and Therapeutic Monitoring, pp. 439455. World Scientific, Singapore (2005)

15. John, B., Tan, B.K., Dainty, S., Spanel, P., Smith, D., Davies, S.J.: Plasma volume, albumin, and fluid status in peritoneal dialysis patients. Clin. J. Am. Soc. Nephrol.5, 1463-1470 (2010)

16. Asghar, R.B., Diskin, A.M., Španěl, P., Smith, D., Davies, S.J.: Influence of convection on the diffusive transport and sieving of water and small solutes across the peritoneal membrane. J. Am. Soc. Nephrol.16, 437-443 (2005)

17. Asghar, R.B., Diskin, A.M., Španěl, P., Smith, D., Davies, S.J.: Measuring transport of water across the peritoneal membrane. Kidney Int. 64, 1911-1915 (2003)

18. Henchman, M., Smith, D., Adams, N.: Proton motion within protonbound dimers: $\mathrm{H}_{3} \mathrm{O}^{+} \cdot \mathrm{H}_{2} \mathrm{O}<->\mathrm{H}_{2} \mathrm{O} \cdot \mathrm{H}_{3} \mathrm{O}^{+}, \mathrm{NH}_{4}{ }^{+} \cdot \mathrm{NH}_{3}<->\mathrm{NH}_{3} \cdot \mathrm{NH}_{4}{ }^{+}$ and $\mathrm{CH}_{5}{ }^{+} \cdot \mathrm{CH}_{4}<->\mathrm{CH}_{4} \cdot \mathrm{CH}_{5}{ }^{+}$- a kinetic-model for isotope-exchange reactions. Int. J. Mass Spectrom. Ion Process. 109, 105-132 (1991)

19. Assonov, S.S., Brenninkmeijer, C.A.M.: A redetermination of absolute values for 17RVPDB-CO2 and 17RVSMOW. Rapid Commun. Mass Spectrom.17, 1017-1029 (2003)

20. Begley, I., Scrimgeour, C.: High-precision ${ }^{2} \mathrm{H}$ and ${ }^{18} \mathrm{O}$ measurement for water and volatile organic compounds by continuous-flow pyrolysis isotope ratio mass spectrometry. Anal. Chem.69, 1530-1535 (1997)

21. Japas, M.L., Fernandez-Prini, R., Horita, J., Wesolowski, D.J.: Fractioning of isotopic species between coexisting liquid and vapor water: complete temperature range, including the asymptotic critical behavior. J. Phys. Chem.99, 5171-5175 (1995)

22. Ross, B.: Sub-parts per billion detection of trace volatile chemicals in human breath using selected ion flow tube mass spectrometry. $B M C$ Res. Notes 1,41 (2008)

23. Smith, D., Pysanenko, A., Španěl, P.: Ionic diffusion and mass discrimination effects in the new generation of short flow tube SIFTMS instruments. Int. J. Mass Spectrom.281, 15-23 (2009)

24. Katsir, Y., Shapira, Y., Mastai, Y., Dimova, R., Ben-Jacob, E.: Entropic effects and slow kinetics revealed in titrations of $\mathrm{D}_{2} \mathrm{O}-\mathrm{H}_{2} \mathrm{O}$ solutions with different $\mathrm{D} / \mathrm{H}$ ratios. J. Phys. Chem. B114, 5755-5763 (2010) 